\title{
Study on Folk Faith Issue in New Rural Reconstruction
}

\author{
Yonglin Lu
}

Northwest Normal University, Lanzhou Gansu, 730070, China

\author{
Keywords: New Rural Reconstruction, Folk Faith Issue, Exploration
}

\begin{abstract}
In China, the folk faith issue has been existing for a long time, and has a far-reaching influence on the thought, way of thinking, social relations and political behaviors of people. With the development of the society and the improvement of economic level, China is accelerating the construction of new socialist countryside, for which the construction of the spiritual civilization is the focal point. Considering the long history of folk faith, it is necessary to deeply research the folk faith issue in new rural reconstruction, so as to facilitate the construction of new socialist countryside faster, better and more comprehensively.
\end{abstract}

\section{Introduction}

New rural reconstruction is a systematic project, involving material civilization construction, political civilization construction and spiritual civilization construction, none of which can be ignored. For a long time, the folk faith issue has been existing in different ethnic groups and regions. Generally, the worship to divinities, nature, ancestors or totem, theocracy, polytheistic worship, and certain utilitarianism are the main features in folk faith. However, folk faith should be regarded as a kind of traditional folk culture in a sense. Actually, the folk faith affecting a large area and having a deep root inevitably will collide with the program of new rural reconstruction. As long as proper measures are taken to draw on advantages and avoid disadvantages, the folk faith issue can show its positive side. In view of this, exploration and research of the folk faith issue are necessary to guarantee the smooth progress of new rural reconstruction.

\section{Analysis of Folk Faith}

Different from the officially institutionalized religious belief, folk faith has its distinctive folk characteristics, mainly including:

\section{Spontaneity}

The subjects of folk faith mainly include peasants, who spontaneously respect and believe in the transnatural spiritual body. The spontaneity is reflected in three aspects:

1). Inorganization. Both the generation and the distribution and hand-down of folk faith reflect the characteristics of groupment. Therefore, there is no standardized and orderly believer management system, and no special management organization has been built for the different sects.

2). Unofficial. Folk faith emerges and develops in rural area, and has never been officially recognized and admitted. Even in the feudal society, the rulers also regarded folk faith as illegal worship activities. Thus, folk faith has been being in an open condition, growing an dying without outside interference[1].

3). Cultural consciousness in hand-down. The main hand-down form of folk faith is oral transmission, which is highly dependent on the habit and cultural consciousness of the believers. So far, almost all the folk faiths in rural area are handed down and preserved by collective conscious inheritance. Although it cannot be said that some specific individual had created the folk faith, it also cannot be denied that individuals had promoted the inheritance process.

\section{Historic Significance and Practical Significance}

Why folk faith can exist throughout the social development and the progress of civilization and survive up to now has much to do with its historic significance and practical significance. The development and inheritance of folk faith cannot be carried out without the practice of the broad 
masses, and influence their ideology, way of thinking and daily production practice in return. Therefore, in order to guarantee spiritual civilization construction in new rural reconstruction, attention should be paid to the mass culture of the grassroots society, to learn about and make extensive research of folk faith as the point of penetrating Chinese society and social culture[2].

\section{Cumulativity}

First, in respect of the emergence and development, folk faith has been being a means for the masses to recognize and manage their life, understand the world, and interact with the world, of which the source of formation and development lies in the animism held by the primitive ancestors. In the primitive society when the society, economy, science and technology were extremely backward, if people could not explain and understand some unreasonable phenomena or social phenomena from the aspect of physical form, they would become feared. In order to relieve the unknown fear, people had no alternative but comfort their emotions through explanation at the spiritual level. Hence, this method was generated, developed and inherited in the fields that people could not understand and grasp with their knowledge and science level, becoming a means of emotional expression for believers in rural area in the scope beyond the mainstream ideology.Second, in respect of the disappearance of folk faith, folk faith in rural area, as a cultural phenomenon similar to class and religion, has reflected the correlations among believers, between believers and other classes, and between believers and nature, and will automatically disappear little by little when conditions permit[3].

Last, the cumulative process of folk faith is full of twists and turns, and of strong vitality, so that folk faith can persist. Specifically, the active degree of a folk faith is closely related to its social background, changes with social change, and reflects obvious periodic characteristics; folk faith can be regarded as a reflection of the real world in the spiritual world of people from ancient times to the present. Besides, the material civilization construction and spiritual civilization construction in rural area are a long-term and arduous task. Therefore, folk faith issue is a long-term issue.

\section{Two Sides of Social Influence}

In respect of social influence, folk faith influences the soul of people first, then controls people's spiritual world, and finally forces the believers whose thought and way of thinking have been controlled to have correspondent behaviors, to exert various influences on society. The influence of folk faith on society includes the positive and the negative. Specifically, in respect of social ethics and value orientation, some concepts advocated in folk faith are reasonable and necessary to some extent, and are favorable for establishing harmonious neighborhood relationship and regional stability. On the other hand, the witchcrafts, superstitions, and heresies prevailing in folk faith greatly hamper the social stability and economic development in rural area, which have polluted the spirit of the broad masses, and have hampered the construction of new socialism countryside from the spiritual aspect. Hence, in the process of new rural reconstruction, the positive part of folk faith should be developed, and the negative part should be put under control, to discard its dregs and absorb the essence and harmonize folk faith and the program of new rural reconstruction.

Besides, folk faith also has the features of secularity, diversity, utilitarianism, and practicability.

\section{Necessity of Research of Folk Faith Issue in the Process of New Rural Reconstruction}

First, the composition of believers becomes more and more complicated. On one hand, as folk faith increasingly prevails, the number of believers takes on an increasing tendency, and there is a large population in rural area in China, who are relatively less literate and liable to fall in superstition. As a result, the believers of folk faith has outnumbered the members in religious faiths. In addition, the number of women staying at home in rural areas who have been supporting the urbanization process silently has greatly risen. Most of them are less literate. Most of them shoulder the heavy responsibility for taking care of their families and the house, face the threat from marriage, and lack cultural life. Thus, they have heavy stress, become sorely in need of a sense of belonging and mental care in the process of overcoming difficulties and managing stress, and join in the group of folk faith 
out of their own needs, sheep mentality and the encouragement and bewitchment of propagators. On the other hand, the group of believers which mainly consisted of the middle-aged, the elderly, the illiterate, the semiliterate and the female is changing its composition, absorbing more and more young persons engaged in different occupations and at different classes[4].

Second, the activities related to folk faith become more and more active. With the improvement of the economic level in rural area, people spend more and more money on building folk faith-related buildings and activities, and various faith-related activities of various forms and on different scales prosper, to which more attention should be paid.

Third, the rituals of folk faith become more and more complicated. Under the context of opening up policy, the rituals held by believers of folk faith become more and more faithful to the ancient ways and solemn, and gradually show the characteristics politicization and commercialization. The tendency of restoring the ancient ways refers to the restoration of some rituals which existed in the past, were preserved after historical sedimentation, but suppressed and denied according to the homogeneity policy formulated after the establishment of the P.R.C. The tendency of becoming solemn refers to that the rich people in rural area input more and more money in various faith-related activities, such as construction of temples and organization of some rituals. However, frequent activities of such kind also bring certain economical burden to peasants. More extremely, such kind of folk faith-related activities are disguised as tourism attraction to make profit in some places, and some ordinary and poor believers are even rejected, isolated or marginalized. The politicization refers to that some official authorities adopt some rituals and activities related to folk faith that have certain political significance and economic value. The commercialization refers to that the symbolic rituals are gradually disguised as commercial activities for profit making, presenting a phenomenon of "economy dances at the stage constructed with faith".

Fourth, folk faith-related activities take on other tendencies. Generally, folk faith-related activities are related to seasons, festivals, weddings, and funerals, having functions of spiritual consolation, moral education, physical and mental pleasure, and facilitating interpersonal communication. Undeniably, these songs, dances and operas for amusing, fawning upon and repaying gods in the past had enriched the culture life in rural area. However, such recreational activities overly prevail in recent years, and develops in the direction of vulgarity, flattery, and philistinism. As a result, folk faith becomes increasingly less holy, more impious, which has greatly hampered the development of folk faith. In addition, a large number of unofficial believers outside of formal administration get together for common faith to form unofficial organizations and become an influential force in the production and living of peasants. Such kind of organizations can be so influential to affect the basic-level election activities, stand up against the public authority, create dissension or discord, etc, to hamper the stability and harmony in rural area.

\section{Effect of Folk Faith on New Rural Reconstruction}

\section{Positive Effect}

First, some concepts and provisions included in folk faith will exert positive effect on people in respect of moral education, including gratitude, awe, praising virtue and punishing vice, loyalty, filial piety, chastity and righteousness, getting along with nature harmoniously, selflessness, which can standardize and restrain people's actions in daily life and production. The worship to nature and soil implies the ethnical thought of environmental protection and conservation of nature. Besides, most local gods were evolved from the virtuous and talented men who upheld justice, strived after virtue, practiced good deeds, or benefited people, and people worship these gods with good wishes for promoting righteousness and correcting social morality. The fear and worship to ancestors is favorable for the inheritance of the fine tradition and virtues of respecting the aged and taking good care of children, and makes for the harmony and stability of family and society.

Second, economic development cannot proceed without cultural construction. Folk faith, as a part of traditional culture and folk custom, also can promote the economic development in rural area to some extent. The cultural exchange in rural area dominated by folk faith can make for the protection 
and inheritance of traditional culture while promoting the local economic interaction and development.

Third, folk faith is a part of ethnic traditional culture, is of strong cohesive force and centripetal force, can strengthen the interrelation among people by integrating people via charism. Take the example of the interrelation among Chinese people in mainland China and other Chinese in Hong Kong, Macao and Taiwan, in which folk faith plays an important role.

Fourth, some fairy tales, lantern show, operas, music and dances prevailing in folk faith have certain research value and heritage value in respect of aesthetics, literature and art, enriched the culture life in rural area, and amused people[5].

\section{Negative Effect}

Combining with decadent ideas, folk faith will dispel and weaken the mainstream ideology to a large extent, such as the conflict between consciousness of ordinary people and patriotism, and between pragmatism and collectivism, etc. Besides, some overseas religious forces even infuse some values and ideas of the west to the mass peasants in the name of folk faith, to weaken the position of the socialist core values in the heart of the public and the influence thereof, which will create development opportunity to the evil organizations or underground religions, and generate religious conflicts or political contradictions to endanger social stability and national security.

Besides, in folk faith, the power of gods are greatly overstated, people are taught to believe in destiny, karma, and yin and yang, people's thoughts are greatly polluted and disturbed thereby, people's optimism spirit is dispelled, and people will lose the ability of distinguishing between right and wrong and between true and false, and are liable to be used by heresies or lawless persons to endanger society and the country.

\section{Conclusion}

New rural reconstruction is an important part and a major approach to realize the construction of socialist modernization, for which consideration should be taken to material civilization construction, spiritual civilization construction and political civilization construction. The long-standing folk faith issue in rural area has a far-reaching influence on the ideology, way of thinking, behavioral habit and recognition of the masses in rural area, and prevails widely in rural areas, becoming a problem that should not be neglected in the process of new rural reconstruction. Thus, it is necessary to make a deep research of the folk faith issue. It should be known that folk faith have both positive and negative effect on new rural reconstruction, the positive side should be correctly guided and developed, and the negative side should be controlled, so as to carry forward the promotion function of folk faith in new rural reconstruction, to facilitate the construction of new socialism countryside.

\section{Acknowledgement}

Research subject of humanistic and social science launched by the Ministry of Education in 2013, Subject name: Research on Folk Culture in Rural Area in Western Region of China and the Modern Significance thereof-Heritage in Lintan County of Gansu Province, An Area between Yangtze River and Huai River, Number: 13YJCZH104

\section{References}

[1] WANG Ruijun. Research on Social Function and Functional Mechanism of Folk Faith-from the Perspective of Construction of New Socialism Countryside. Nanjing University of Aeronautics and Astronautics, 2012.

[2] TIAN Chong. Folk Faith in the Social Transition Period and Evolution thereof-Case Study of Folk Faith in Daguangyao Village in Central Shandong Area. South Central University for Nationalities, 2010. 
[3] LIU Ying, WANG Yanqiu. Thinking on Theories and Policies of Folk Faith. Theory Horizon, 2013(9): 113-115.

[4] PENG Peng, HE Hua. Reconstruct Folk Spiritual Home: Survey and Anlysis of Folk Faith. Journal of Nanjing Party Institute of CPC, 2013(5): 82-87.

[5] WU Liping. Emphasis should be laid on folk faith in the process of promoting the popularization of Marxism. Journal of Wuling, 2013(4): 45-49. 